Int. J. Electrochem. Sci., 15 (2020) $526-534$

International Journal of

ELECTROCHEMICAL

SCIENCE

WWW.electrochemsci.org

\title{
Complex Hollow Structures of Cobalt(II) Sulfide as a Cathode for Lithium-Sulfur Batteries
}

\author{
Miaomiao Li $^{2}$, Wangjun Feng ${ }^{1,2 *}$, Xuan Wang ${ }^{1,2 *}$ \\ ${ }^{1}$ State Key Laboratory of Advanced Processing and Recycling Nonferrous Metals, Lanzhou University \\ of Technology, Lanzhou 730050, China; \\ ${ }^{2}$ School of Science, Lanzhou University of Technology, Lanzhou 730050, China \\ *E-mail: wjfeng@lut.cn, wangxuan2010@lut.cn
}

doi: $10.20964 / 2020.01 .77$

Received: 8 September 2019 / Accepted: 9 November 2019 / Published: 30 November 2019

Lithium-sulfur batteries are considered the most promising candidates in the next generation of electrochemical energy storage because of their huge advantages in energy density, coulombic efficiency and price. One of the problems to be solved is promoting the conversion of polysulfides while maintaining high sulfur utilization. Complex double-layered hollow nanostructures have attracted wide attention as battery cathode materials. A ZIF-67 nanocube is used as a template to form a double-layer hollow structure (denoted as CoS) in which the inner layer is a CoS nanobox and the outer shell is a CoS nanosheet. In general, the double-layer hollow structure not only maximizes the encapsulation of sulfur but also provides sufficient reaction sites to optimize the electrochemical properties of the material. As a cathode material for Li-S batteries, cobalt-based sulfides also improve electrochemical performance due to their high electronic conductivity and abundance of redox reaction sites. The initial discharge capacity of the battery at $0.1 \mathrm{C}$ was $1275.76 \mathrm{~mA} \mathrm{~h} \mathrm{~g}{ }^{-1}$, demonstrating excellent rate performance.

Keywords: Lithium-sulfur batteries; ZIF-67 nanocube; double-layer hollow structure; cathode

\section{FULL TEXT}

(C) 2020 The Authors. Published by ESG (www.electrochemsci.org). This article is an open access article distributed under the terms and conditions of the Creative Commons Attribution license (http://creativecommons.org/licenses/by/4.0/). 